\title{
LIST STAR EDGE-COLORING OF SUBCUBIC GRAPHS
}

\author{
SAmia KeRdJOUdJ \\ L'IFORCE, Faculty of Mathematics \\ USTHB, BP 32 El-Alia, Bab-Ezzouar 16111, Algiers, Algeria \\ e-mail: s_kerdjoudj@yahoo.fr \\ Alexandr KostochKa ${ }^{1}$ \\ University of Illinois at Urbana-Champaign \\ Urbana, IL 61801, USA and Sobolev Institute of Mathematics \\ Novosibirsk 630090, Russia \\ e-mail: kostochk@math.uiuc.edu. \\ AND \\ ANDRÉ RASPAUD ${ }^{2}$ \\ LaBRI (Université de Bordeaux), 351 cours de la Libération \\ 33405 Talence Cedex, France \\ e-mail: andre.raspaud@labri.fr
}

\begin{abstract}
A star edge-coloring of a graph $G$ is a proper edge coloring such that every 2-colored connected subgraph of $G$ is a path of length at most 3. For a graph $G$, let the list star chromatic index of $G, c h_{s t}^{\prime}(G)$, be the minimum $k$ such that for any $k$-uniform list assignment $L$ for the set of edges, $G$ has a star edge-coloring from $L$. Dvořák, Mohar and Šámal asked whether the list star chromatic index of every subcubic graph is at most 7 . We prove that it is at most 8 . We also prove that if the maximum average degree of a subcubic graph $G$ is less than $\frac{7}{3}$ (respectively, $\frac{5}{2}$ ), then $c h_{s t}^{\prime}(G) \leq 5$ (respectively, $c h_{s t}^{\prime}(G) \leq 6$ ).
\end{abstract}

Keywords: graph coloring, edge coloring, star coloring, planar graphs. 2010 Mathematics Subject Classification: 05C15.

\footnotetext{
${ }^{1}$ Research of this author is supported in part by NSF grant DMS-1266016 and by grant 15-01-05867 of the Russian Foundation for Basic Research.

${ }^{2}$ This study has been carried out with financial support from the French State, managed by the French National Research Agency (ANR) in the frame of the "Investments for the future" Programme IdEx Bordeaux - CPU (ANR-10-IDEX-03-02).
} 


\section{REFERENCES}

[1] O.V. Borodin, Criterion of chromaticity of a degree prescription, in: Abstracts of IV All-Union Conf. on Theoretical Cybernetics, Novosibirsk (1977) 127-128, in Russian.

[2] L. Bezegova, B. Lužar, M. Mockovčiaková, R. Soták and R. Škrekovski, Star edge coloring of some classes of graphs, J. Graph Theory 81 (2016) 73-82. doi:10.1002/jgt.21862

[3] K. Deng, X.S. Liu and S.L. Tian, Star edge coloring of trees, J. Shandong Univ. Nat. Sci. 46 (2011) 84-88, in Chinese.

[4] Z. Dvořák, B. Mohar and R. Šámal, Star chromatic index, J. Graph Theory 72 (2013) 313-326. doi:10.1002/jgt.21644

[5] G. Fertin, A. Raspaud and B. Reed, On star coloring of graphs, Lecture Notes in Comput. Sci. 2204 (2001) 140-153.

doi: $10.1007 / 3-540-45477-2 \_14$

[6] B. Grünbaum, Acyclic colorings of planar graphs, Israel J. Math. 14 (1973) 390-408. doi: $10.1007 / \mathrm{BF} 02764716$

[7] H. Hocquard, M. Montassier, A. Raspaud and P. Valicov, On strong-edge coloring of subcubic graphs, Discrete Appl. Math. 161 (2013) 2467-2479. doi:10.1016/j.dam.2013.05.021

[8] A.V. Kostochka, M. Stiebitz and B. Wirth, The colour theorems of Brooks and Gallai extended, Discrete Math. 162 (1996) 299-303. doi:10.1016/0012-365X(95)00294-7

[9] X.S. Liu and K. Deng, An upper bound on the star chromatic index of graphs with $\delta \leq 7$, J. Lanzhou Univ. (Nat. Sci.) 44 (2008) 94-95.

[10] H. Zhu and Z. Miao, On strong list edge coloring of subcubic graphs, Discrete Math. 333 (2014) 6-13.

doi:10.1016/j.disc.2014.06.004

Received 16 September 2015

Revised 11 May 2017

Accepted 11 May 2017 